\title{
ESTUDO SOBRE A REDUÇÃO DE CUSTO DE ESTOCAGEM E MANUSEIO EM PÁTIOS DE BOBINA A QUENTE*
}

Fernando de Jesus Guerra ${ }^{1}$

\section{Resumo}

Este trabalho apresenta de forma sucinta um estudo sobre modificações na estratégia de gestão e nos sistemas de informação dos pátios de bobina a quente que trarão redução no custo de manuseio e estocagem nos mesmos. O estudo baseia-se na observação direta e objetiva dos métodos utilizados por várias empresas no Brasil e no exterior. Nossa conclusão é que a abordagem proposta resulta em significante redução de custos.

Palavras-chave: Gestão de pátios; Sistemas de otimização logística; Monitoramento de materiais.

\section{STUDY ABOUT COST REDUCTION REGARDING MATERIAL HANDLING AND STOCKING ON HOT COIL YARDS}

\section{Abstract}

This paper briefly presents a study about changes to be made on hot coil yards management strategy and information systems that will result in cost reduction. The study is based on direct objective observations made about the methods and strategies utilized by companies in Brazil and abroad. Our conclusion is that companies that utilize the proposed strategy will achieve significant cost reduction in the area.

Keywords: Yard management; Logistic optimization solutions; Material tracking. 


\section{INTRODUÇÃO}

No atual momento econômico brasileiro a redução de custos torna-se uma questão de sobrevivência para a indústria nacional. Para a siderurgia o momento é ainda mais complicado, com achatamento das margens, aumento do endividamento e a concorrência de importação de produtos siderúrgicos, principalmente da China.

Em nossas observações em diversos clientes no Brasil e em outros países tivemos a oportunidade de identificar alguns processos onde há grande espaço para aumentar a eficiência da indústria nacional de aço. Dentre estes processos selecionamos o de gestão de pátios para um estudo mais profundo, pois acreditamos que este é um processo onde há bastante espaço para redução de custos e aumento de produtividade. Decidimos por focar em pátios de bobinas a quente para permitir uma comparação entre diversos casos práticos na gestão relacionada a um mesmo tipo de material

Iniciaremos este estudo descrevendo situações típicas encontradas em diversas empresas. Apresentaremos os problemas causados pelos métodos e tecnologias mais utilizados. A partir daí, descreveremos uma abordagem integrada com outros processos e utilizando tecnologias atuais que permitirão redução de custos e ganho de produtividade na gestão dos pátios de bobinas a quente.

Salientamos que os mesmos princípios aqui descritos podem ser aplicados a pátios para outros tipos de produto siderúrgicos. Muitos dos problemas encontrados e das soluções propostas independem do tipo de material e estão ligados às práticas atuais de gestão.

\subsection{Visão Geral Sobre Pátios de Bobinas a Quente}

Algumas características tornam a gestão de pátios de bobinas a quente especialmente difícil.

Os Laminadores de Tiras a Quente produzem em ritmo bastante acelerado. Tipicamente uma nova bobina é criada a cada 2 a 5 minutos, dependendo do laminador. Isso significa que muitas vezes as pontes rolantes da área de estocagem na saída do laminador são gargalos para movimentação de materiais.

Além disso, ao final do processo de bobinamento as peças têm temperaturas superiores à $300^{\circ} \mathrm{C}$. Isso dificulta o processo de identificação do material. Em muitas usinas a identificação de cada bobina é escrita a giz pelos operadores de pátio.

Outra dificuldade é o tempo de permanência dos materiais em estoque enquanto aguardam atingirem temperaturas que permitam o despacho ou a produção nos processos seguintes. Dependendo do método de resfriamento uma bobina pode ter que aguardar até nove dias em estoque para ser liberada. Isso significa que o volume armazenado nestes pátios é sempre bastante elevado.

Outro ponto é que os diferentes métodos de resfriamento e a diferença de temperatura entre bobinas recém-produzidas e aquelas que já estão em estoque por algum tempo impõe restrições sobre os locais que podem ser utilizados para armazenagem. Por exemplo, bobinas recém-produzidas não podem ser armazenadas muito próximas àquelas que já estão resfriando a mais de um dia ou elas causarão um aumento na temperatura destas. Outro exemplo é a divisão da área de resfriamento de acordo com o tipo deste: forçado à água, forçado a ar ou resfriamento natural. Muitas vezes o processo de resfriamento forçado à água destrói a identificação das peças quando esta é por marcação a giz. 
Por fim, existem ainda restrições de empilhamento do material que forçam limitações adicionais no armazenamento. Estas limitações estão ligadas, principalmente, à características dimensionais do material. Por exemplo, se as bobinas são armazenadas no eixo vertical, aquelas com maior diâmetro tem de ficar no 'fundo' da pilha.

\section{2 'Agrupamento de Materiais’}

O processo atual de gestão de pátios de bobina a quente tenta endereçar estas dificuldades utilizando alguns métodos e tecnologias muitas vezes ultrapassados.

Em quase todas as empresas no Brasil algum tipo de agrupamento é feito com base em características físicas do material para facilitar o trabalho de estocagem e manuseio.

Um exemplo típico é a criação de grupos de peças intercambiáveis, ou seja, que podem substituir umas às outras e que, tipicamente, sejam produzidas juntas nos laminadores e processos subsequentes. Assim, mesmo que haja troca entre as peças os requisitos e as normas de produção ainda serão atendidos.

Esse método tem a vantagem de reduzir o manuseio, pois permite que sempre a peça de mais fácil remoção (a do 'topo' da pilha, por exemplo) seja utilizada primeiro. Mas ele impõe restrições adicionais ao sequenciamento de produção dos laminadores e dos processos subsequentes, uma vez que pressupõe que todo o 'grupo' deve ser processado junto. Nos casos em que isso não acontece, ele acaba por impor outros problemas, como a subutilização de espaços de estocagem.

\subsection{Pseudo-otimização com Base em Atributos Físicos}

Outro método bastante utilizado é a tentativa de 'otimizar' os pátios criando algoritmos caseiros para 'sugerir' locais de estocagem. Tipicamente estes algoritmos utilizam apenas características físico-químicas dos materiais para realizar a otimização.

Embora este método represente um avanço significativo em relação ao método anterior de simples 'agrupamento' de peças, ele tende a causar problemas semelhantes, uma vez que pressupõe a mesma premissa de que alguns materiais devem ser produzidos em conjunto e quando isso não ocorre, o que é frequente, a utilização de espaços fica comprometida.

Outro aspecto negativo deste método é que ele tende a aumentar antecipação e os atrasos em relação à data planejada de produção.

\subsection{Sistemas de Informação na Gestão de Pátios}

Em muitos casos encontramos também sérios problemas nos sistemas de informação utilizados na gestão dos pátios de bobinas a quente.

Em muitas empresas, os pátios não são totalmente mapeados em seus três eixos e o endereço lógico do material limita-se à identificação de uma baia, fila ou pilha.

Também é comum termos a execução da movimentação e o registro da mesma na mão de operadores diferentes. Enquanto um operador no 'chão' decide sobre a movimentação, a execução dela é feita por outro operador na ponte rolante recebendo instruções por rádio do primeiro. Posteriormente o registro dessa movimentação é feito pelo operador no 'chão'. Isso cria um descompasso entre execução e informação 
Outra limitação típica desses sistemas diz respeito à atualização off-line da informação de movimentação.

Em alguns casos, os operadores utilizam relatórios impressos com a lista de materiais a serem estocados e/ou removidos e registram manualmente neles o 'novo' endereço de cada bobina movimentada. Posteriormente os operadores dirigem-se a uma cabine onde digitam as informações coletadas.

Em outros casos, os operadores utilizam 'coletores de dados' para informar sobre a movimentação. Mas mesmos neste o mais comum é que exista apenas um 'pick-list' dos materiais que devem ser recebidos e/ou removidos, sem qualquer critério de prioridade e/ou sugestão de estocagem. Em alguns sistemas os coletores atualizam as informações on-line e, em outros, as informações são baixadas somente quando o operador chega a algum ponto coberto pela rede de dados.

Por fim, quase todos os sistemas atualmente em uso limitam-se a fornecer aos operadores uma lista de materiais que irão chegar ao pátio e uma lista a ser removida para equipamentos posteriores e/ou áreas de embalagem para despacho. Isso quer dizer que não há planejamento das movimentações.

O resultado mais direto destas limitações dos sistemas de informação atuais é a perda de acuracidade relativas as informações de estoque, tanto no que diz respeito a volume, quanto à onde efetivamente se encontra cada peça.

\subsection{Efeitos Negativos dos Métodos e tecnologias Atualmente em Uso}

Esses métodos e limitações tecnológicas dos atuais sistemas causam diversos efeitos negativos para os resultados das empresas.

Um efeito fácil de ser identificado e medido é o retrabalho causado pela necessidade constante de recontagem dos estoques no pátio para reconciliar as informações contidas no sistema de gestão com a real situação do pátio.

Outro efeito importante é o elevado número de movimentações realizadas desnecessariamente devido à falta de planejamento de armazenagem/remoção de materiais.

Este efeito é especialmente importante, pois as pontes rolantes dos pátios de bobina a quente (BQ) costumam trabalhar perto de seu limite e o excesso de montagem/desmontagem de pilhas para movimentar poucas peças costuma transformar estas pontes em efetivos gargalos que limitam a produtividade do LTQ e de outros equipamentos.

A falta de acuracidade sobre os locais de estocagem causa ainda dois problemas onerosos às empresas.

O primeiro deles é a 'perda' temporária de bobinas. Elas estão no pátio, mas não são achadas em tempo de serem movimentadas para a área de carregamento do equipamento seguinte, causando perda de produção, quebra de sequencia e, por vezes, atrasos no processamento de pedidos de clientes.

O segundo deles é que às vezes a perda de acuracidade soma-se à perda da identificação do material. Então, para que ele possa ser reaproveitado, é necessária uma reinspeção para identificar características dimensionais e de superfície e reamostragem para determinar atributos mecânicos e metalúrgicos. Além dos custos evidentes relacionados à reinspeção e reteste dos materiais existem outros menos óbvios relacionados ao atraso no processamento, como a perda do prazo de entrega e o aumento do capital imobilizado.

Por fim, em casos extremos chega-se a ter parada de produção dos laminadores por 'falta de espaço' nos pátios de BQ, causando efetiva perda de produção e receita. 


\subsection{Abordagem Proposta para a Gestão de Pátios}

A abordagem que propomos para enfrentar todos os problemas listados no cenário acima e reduzir os custos de estocagem e manuseio de bobinas a quente baseia-se na observação realizada em diversos clientes que tiveram sucesso em alcançar índices melhores de aproveitamento de seus pátios e reduziram a virtualmente zero as perdas com os ditos problemas.

Os ponto-chaves da abordagem estão ligados tanto a métodos e processos de gestão como a novos sistemas de informação e baseiam-se nas seguintes premissas:

- As estratégias de estocagem/manuseio de materiais precisam levar em conta não só características físicas das peças, mas também dados de planejamento e sequenciamento da produção para gerar listas ótimas de movimentação, através do uso de algoritmos avançados de otimização;

- Os sistemas de informação devem armazenar as coordenadas completas de endereço do material (três eixos);

- As movimentações de materiais, via de regra, devem ser decididas previamente e os operadores devem receber ordens de transporte completas dizendo que peças devem ser movidas com seus respectivos 'endereços' de origem e destino. A decisão deve caber aos operadores somente em caso de exceção e/ou contingencia;

- As informações devem ser atualizadas o mais próximo possível do momento da execução (on-line/síncrono) e preferivelmente pelo mesmo operador que realiza a movimentação.

Com base nestas premissas o que propomos é a implantação de um sistema de gestão integrado com os sistemas responsáveis pelo planejamento e programação da produção.

Essa integração permite que seja criado um plano de estocagem e manuseio prévio que leve em consideração a sequencia em que o material será produzido e consumido.

Onde os sistemas de APS (advanced planning and scheduling, ou sistemas avançados de planejamento e sequenciamento) são limitados ao planejamento da produção o sistema de logística do pátio deve conhecer ao menos as datas planejadas de produção dos materiais, para, somando esta informação às características físicas, criar um plano de manuseio que contemple entre outras coisas prioridades dos clientes.

Se o sistema de APS for mais avançado e permitir a programação de material 'virtual' nas linhas subsequentes ao laminador, o sistema de logística deve levar em conta a sequencia de produção do LTQ e dos equipamentos seguintes criando um plano realmente ótimo de movimentação que leva em conta atributos físicos e a sequencia de chegada/saída de peças do pátio. Desta forma, no momento em que uma peça é colocada em estoque já se sabe quando ela será retirada e para onde.

Em ambos os casos o importante é que exista um plano prévio de movimentação que deve ser seguido pelo operador. Se uma pilha precisa ser desmontada para a retirada de uma peça, todos os movimentos relativos a esta desmontagem devem constar do plano. O plano deve ainda conter os endereços de origem e destino de cada peça, retirando das mãos do operador a decisão sobre os movimentos. Isso é importante porque as informações a que os operadores de pátio têm acesso são bastante limitadas e não permitem que eles tenham uma visão global sobre os impactos de suas decisões. 
Para enfrentar a questão da falta de acuracidade, o sistema de gestão tem que permitir o mapeamento do pátio em três eixos e armazenar o endereço completo do material. Também é desejável que esta atualização seja feita imediatamente após a execução de qualquer movimentação.

Existem sistemas de mercado que permitem que esta atualização seja feita pelo próprio operador da ponte rolante com o uso de tablets conectados através de rede wireless.

Alguns sistemas mais avançados utilizam sensores de radar, laser ou até mesmo GPS para monitorar os movimentos das pontes rolantes e registrar qualquer movimentação de peças de forma automática, sem se quer necessitar de intervenção manual.

Salientamos que mais importante que as tecnologias utilizadas é o processo de gestão em si. Os sistemas de informação servem apenas como 'facilitadores' para a execução de uma estratégia. No entanto, sem sistemas adequados é impossível processar todas as informações necessárias para que a abordagem seja posta em prática.

\section{MATERIAIS E MÉTODOS}

Este trabalho baseia-se na observação direta de casos práticos em diversas usinas no Brasil e em outros países. Também utilizamos como fontes benchmark realizados com nossos clientes.

\section{RESULTADOS E DISCUSSÃO}

Nos poucos casos em que as empresas realizaram a mudança da estratégia dominante no mercado para a abordagem descrita neste trabalho com a utilização de seus métodos e tecnologias, verificamos drásticas melhorias quantitativas e qualitativas na gestão dos pátios de $B Q$.

Entre os resultados, destacam-se os seguintes:

- Drástica melhora na acuracidade da informação sobre o local de estocagem de cada peça, elevando o índice acima de 99\% onde tecnologias de rastreamento automático das pontes rolantes são aplicadas;

- Redução dos eventos de recontagem/reconciliação de estoque para o mínimo necessário para efeito contábil e consequente eliminação dos custos de retrabalho relacionados a estes eventos;

- Eliminação das ocorrências de perda de produção por 'falta' de material nas linhas subsequentes ao pátio de BQ's causadas por falta de sincronia entre a informação constante no sistema e a real situação dos pátios de estocagem;

- Drástica redução de movimentações desnecessárias de materiais com consequente redução da utilização das pontes rolantes e da ocorrência de eventos que as tornam gargalo para a produção;

- Eliminação dos eventos de reamostragem/reinspeção de materiais devido a perda da informação sobre que peças estão estocadas em que locais.

\section{CONCLUSÃO}

Nossa conclusão é que a alteração na abordagem nos processos de gestão de pátio de BQ's para a estratégia descrita neste trabalho trará ganhos financeiros e qualitativos para as empresas que a realizarem. 
Estes ganhos estão manifestam-se da seguinte forma:

- Redução de custos com retrabalho, reamostragem e reinspeção;

- Redução de custo de manuseio, com a eliminação de movimentos desnecessários;

- Redução do imobilizado atingida pela redução de materiais parados no pátio por falta de identificação;

- Aumento de produtividade das linhas subsequentes ao pátio de BQ's através do aumento da disponibilidade de materiais para produção;

- Redução da exposição ao risco e cargas suspensas através da redução de necessidade de operados no 'chão' do pátio;

- $\mathrm{E}$, em alguns casos, redução de headcount devido eliminação de postos de trabalho de operados no 'chão'. 